\title{
La cosmología de lo neobarroco: la función de la astronomía dentro de la poesía de Severo Sarduy y Haroldo de Campos
}

\author{
Vaughn Anderson ${ }^{\bullet}$ \\ Maryville University
}

\section{Resumen}

Al utilizar la ciencia astronómica como una base teórica o armazón conceptual para su poética neobarroca durante los años '70 y '80, el poeta cubano Severo Sarduy y el brasileño Haroldo de Campos participan en una tradición poética que proviene del poeta francés Stéphane Mallarmé, quien usó el concepto de la constelación para caracterizar la tipografía dispersa de su famoso poema experimental, Un Coup de dés (1914). Sin embargo, Sarduy y de Campos aprovechan esta idea de la constelación sólo como punto de partida. Ambos poetas van más allá de la constelación para convertir en poesía varias otras teorías científicas emergentes del día: el Big Bang, la deriva espacial, la materia oscura, etc. Así, estos dos poetas logran dramatizar la manera en que el lenguaje, igual que el universo que representa, se define por la incertidumbre, la ausencia y la inefabilidad.

\author{
Palabras clave \\ - neobarroco · astronomía · poesía · experimental
}

\begin{abstract}
In using astronomical phenomena as a conceptual model for their poetics, Cuban poet Severo Sarduy and Brazilian Haroldo de Campos position themselves within a poetic tradition that they trace back to the French poet Stéphane Mallarmé, who famously used the idea of a constellation to describe the scattered typography of his monumental poem, $U n$
\end{abstract}

- NTT Assistant Professor of English en la Maryville University, Saint Louis, Estados Unidos. Sus investigaciones se enfocan en la poesía experimental, la traducción literaria, y los estudios trans-americanos. Es doctor en Literatura Comparada por la Rutgers University, New Brunswick, New Jersey, Estados Unidos. Resultados de su trabajo se ha publicado en Hispanic Journal, Journal of Modern Literature, Comparative American Studies, entre otros. 
Coup de dés (1914). However, Sarduy and de Campos take the constellation merely as a point of departure, repurposing new and groundbreaking astronomical theories (like the Big Bang and galactic drift) as paradigms for their Neobaroque poetics. I argue that astronomy provides a generative foundation for Neobaroque poetics not because it expands our knowledge of the universe but because it highlights gaps in that knowledge. It allows these poets to dramatize the ways in which language, like the universe it describes, is defined by uncertainty, lack, and ineffability.

\section{Key words}

- Neobaroque · Astronomy · Poetry · Experimental

En el año 1973, el poeta cubano Severo Sarduy publicó un libro de poemas titulado Big bang. En la portada del libro aparece un diagrama programático de los elementos básicos de nuestro sistema solar: planetas, asteroides, caminos orbitales. A primera vista el libro parece más un manual básico de astronomía que un libro de poemas. De hecho, varios de los textos recolectados adentro son pasajes, traducciones, o paráfrasis directas de obras científicas de astrónomos notables como Georges Lamaittre, Herbert Friedmann, y Allan Sandage. Uno de los textos del volumen, presentado bajo el encabezado «Big bang» sirve de ejemplo:

Las galaxias parecen alejarse unas de otras a velocidades considerables. Las más lejanas huyen con la aceleración de doscientos treinta mil kilómetros por segundo, próxima a la de la luz. El universo se hincha.

Asistimos al resultado de una gigantesca explosión.

«Big bang» es el primer texto que se incluye dentro de una sección del libro que también se llama Big bang, que a su vez hace parte de las tres otras secciones del libro de poemas. El poema describe la idea de deriva espacial, el movimiento perpetuo de las galaxias que siempre se alejan de un centro universal, el sitio del Big Bang mismo. Cuando Sarduy publicó su volumen de poesía en 1973, la idea de la deriva espacial sólo se había confirmado unos 10 años antes, reemplazando a la teoría del estado estacionario, modelo astronómico según el cual la densidad de la materia del universo se mantiene constante a pesar de que el universo siempre se expande. En Big bang, la dispersión acelerada de la deriva espacial se hace central para la analogía que Sarduy establece entre la astronomía y el lenguaje: las estrellas y las palabras. Al tiempo que Sarduy narra el proceso del nacimiento del universo «una aglomeración incompleta y decadente de objetos celestiales», sugiere que este proceso es análogo al de componer (o al de descifrar) los fragmentos del 
libro mismo. Dentro de la poética neobarroca de Sarduy, el lenguaje, igual que el universo, siempre se encuentra en un proceso de disolución, suelto (¿libre?) y sin ningún centro coherente.

Este artículo se propone explorar la analogía neobarroca entre el lenguaje y la astronomía por medio de un análisis de Big bang junto con dos otros libros de poesía más o menos contemporáneos del libro de Sarduy: Xadrez de estrelas (1976) y Galáxias (1986), del poeta brasileño Haroldo de Campos. Para los dos poetas, la astronomía les provee un paradigma idóneo para una poética posmoderna y neobarroca precisamente porque permite conceptualizar y dramatizar de una forma innovadora nuestro conocimiento incompleto y experimental tanto del universo, como del lenguaje que usamos para representarlo.

\section{El espacio vacío y la materia oscura}

El aspecto visual es el que a primera vista más llama la atención tanto de Big bang como de la obra poética-astronómica de Haroldo de Campos. Sarduy y de Campos juegan con la tipografía y puesta en papel de una forma que imita los fenómenos astronómicos que se describen dentro de los poemas. Por ejemplo, en Big bang, encontramos poemas como «Sol»:

limón faisán blanco
los pies desnudos polvo de azafrán seco
en el agua al revés la muralla
zumbido
círculo
sol

El poema es una colección de imágenes semi-dispersas, realizado con una economía verbal que imita al lenguaje minimalista del haiku japonés. Como si fuesen esparcidas por el «big bang» del título, las palabras del poema no se mantienen unidas por ninguna sintaxis perceptible. Sin embargo, poco a poco se reúnen para formar una escena: con los pies en el agua, alguien se sienta al lado de un estanque mientras el sol se refleja en el agua. Como muchos de los poemas en Big bang, las relaciones entre las palabras del poema son tan visuales como gramaticales. En cuanto a su organización en la página, las palabras se van juntando mientras se acercan a la palabra «sol». Esto sugiere otra imagen muy distinta de la de un tableau pintoresco: el pozo de gravedad que rodea cada estrella. El «círculo» que vemos en el poema ya no es una ola en un estanque sino una órbita como las que aparecen en la portada del libro.

De manera similar a Sarduy, de Campos usa la astronomía como concepto literario para reunir una amplia y diversa selección de textos propios. En 1974, bajo el título de Xadrez de estrelas: Percurso textual 1949-1974, el brasileño publica un una colección retrospectiva en la cual compila obras que había publicado a lo largo de los veinticinco años previos. Como en Big bang, cuyo título implica una poética de gravitación y dispersión, el título de Xadrez de estrelas sirve para caracterizar la labor que la obra exige del lector. Las palabras se disuelven en fonemas sueltos que se dispersan por las páginas, lo que hace necesario una forma de leer no convencional. 


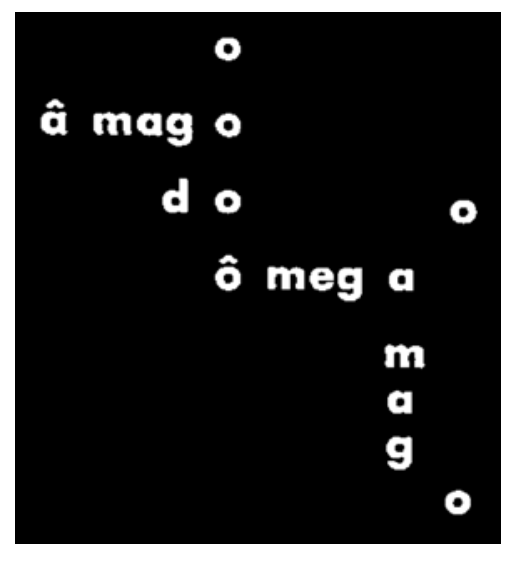

A veces resulta más apropiado leer de abajo hacia arriba, o de derecha a izquierda - o hasta de forma serpenteante, trazando las constelaciones barrocas a las que se refiere el título de la obra. El poema "O âmago do ômega» nos sirve de ejemplo. A pesar de la insistencia constante de los concretistas de que la (¿organización de las palabras sobre el papel?) en sus poemas no sirve como representación visual, aquí las palabras blancas contra un fondo negro claramente sugieren una representación de un cielo nocturno lleno de estrellas. Hasta el título mismo del poema enfatiza esta analogía.

Las repetición de las letras «o» $\mathrm{y}$ «a» del título crean aquí una sugerencia visual de estrellas contra el cielo oscuro. De modo parecido, los poemas que siguen se llenan de palabras y frases que se dispersan y se reúnen para formar constelaciones que a veces pueden ser reglamentadas y geométricas, pero que con más frecuencia parecen haber sido esparcidas al azar por una fuerza propia a la poesía misma —una suerte de «big bang» poético como el del libro de Sarduy. En la primera sección de Xadrez de estrelas, el estallido inicial de palabras y frases poco a poco se fragmenta en agrupaciones cada vez más incoherentes de sílabas sueltas para finalmente encontrar, al pie de la última página, las letras "ps», una posdata vacía y sin ningún sentido.

Gracias a su uso de la astronomía —y de la constelación en particular- como concepto poético, de Campos y Sarduy su participan en una tradición poética que empieza con la obra Stéphane Mallarmé, poeta francés que usó la idea de la constelación para describir la tipografía de su poema «Un Coup de dés» (1914), primera obra maestra de la poesía visual. Sin embargo, mientras que Sarduy y de Campos emplean el término "constelación» para describir (¿poemas o poesías?) en las que el espacio de la página interrumpe o altera el funcionamiento normal de la sintaxis, enfatizando, de esta suerte, la importancia de las conexiones visuales, Mallarmé describe su poesía como fundamentalmente discursiva. Esto se ve claramente en su introducción al poema:

Los «blancos» en efecto adquieren una importancia, afectando principalmente; la versificación exige, como silencio aledaño, habitualmente, hasta el punto de que un pieza, lírica o de "peu de pieds", ocupa el medio, aproximadamente una tercera parte de la hoja; yo no transgredo esta medida, solamente la disperso ${ }^{1}$ (Mallarmé 121).

Como Marjorie Perloff nota en su análisis del pasaje: «the conventions of phrasal and clausal structure remain intact» en "Un Coup de dés», a pesar de su apariencia dispersa («Refiguring» 40). El título de Xadrez de estrelas —igual a Big bang — sugiere una afinidad poética con la tradición mallarmeana, pero al mismo tiempo señala que de Campos lleva la alegoría astronómica más allá de la constelación. Mallarmé dice que su propia poesía no "transgresse cette mesure», así preservando la calidad discursiva del verso tradicional, pero para de Campos la constelación poética funciona como un ideograma, definida por relaciones no sintácticas, sino espaciales y visuales ${ }^{2}$. 
En su «Plano piloto poesía concreta», los poetas Noigandres citan como influencia trascendental la idea de Mallarmé de las "subdivisions prismatiques de l'idée"; espaço ("blancs") e recursos tipográficos como elementos substantivos da composição" (Teoria da poesia concreta 215). Sin embargo, para los poetas brasileños, la idea de la constelación inspira un uso de la página que es totalmente distinto del elaborado por Mallarmé. Como nota Wendy Steiner, «cuando los concretitas representaron lo que puede considerarse el silencio mallarmeano, (...) lo que efectivamente consiguieron fue la reificación del silencio en sí mismo, una inversión de la ausencia marcando el intento convencional de hacer una poética de la presencia» " «Res Poetica» 538). A diferencia de «Un Coup de dés», donde la palabra se transforma en idea pura, la poesía de los hermanos de Campos trata a la página blanca como materia propia de la poesía, capaz de cambiar o interrumpir el significado de las palabras.

\section{La deriva galáctica y la deriva semántica}

Octavio Paz, colega y contemporáneo de Sarduy y de Campos, dice que para los místicos medievales, el lenguaje obedecía las leyes de la naturaleza, así «fundado en la armonía cósmica» (Los hijos del limo 101). No era necesario reconciliar las palabras con las cosas porque la fuerza que las unía - la analogía - se consideraba una ley universal. Paz lo explica así:

La creencia en la analogía universal está teñida de erotismo: los cuerpos y las almas se unen y separan regidos por las mismas leyes de atracción y repulsión que gobiernan las conjunciones y disyunciones de los astros y de las sustancias materiales. Un erotismo astrológico y un erotismo alquímico (101).

Durante el periodo pre-moderno, Paz señala que los filósofos creían que el lenguaje obedecía las leyes de la astrología; indistinguibles de las leyes de la magia. Este pasaje de Los hijos del limo está marcado por la nostalgia porque, como Paz nos cuenta, él narra la historia desde el espacio vacío que la literatura moderna ha conservado en memoria de esta visión perdida del universo. Según Paz, «el centro de la analogía es un centro vacío para nosotros» (111). Al centro de la analogía cósmica no se encuentra la Palabra sino su ausencia: el silencio. En su famoso poema Blanco (1967), así como en sus ensayos de fines de los años '60, Paz dice que el silencio, y no el lenguaje, nos da una imagen fiel del universo.

Sarduy y de Campos dan vuelta la nostalgia de Paz. Para ellos, el silencio no representa la pérdida de una imagen coherente del universo, sino el descubrimiento de un modelo más fiel de la realidad. De Campos y Sarduy aceptan que el hecho de que las palabras que usamos para describir al mundo carecen de cualquier significado intrínseco. Para ellos, esta carencia señala que el lenguaje mismo se funda en el vacío. El vacío es el resultado de la naturaleza contingente, relacional e inestable de todo significado, y de la relación arbitraria entre el significado y el significante. Aquí la fuerza generativa no es la analogía sino la diferencia, la precondición inherente de un sistema linguístico donde todo significado es relacional y circunstancial. Aquí, el Big Bang es el punto universal del no-origen ${ }^{4}$. Juntos, 
Sarduy y de Campos reclaman la idea de la escritura como reflejo de los cosmos - no por haber ningún enlace entre las palabras y las cosas, sino por la vacuidad de la cual todas las palabras y las cosas emergen.

En «O âmago do ômega», de Campos da forma visual a su idea de la ausencia como presencia. Aquí la relación entre el texto y la página se invierte: el poeta pone la letra blanca en un fondo negro para permitirnos ver de nuevo el acto de escribir. Normalmente la escritura sería un proceso de poner marcas sobre la página blanca, pero aquí las palabras mismas son la página vacía, que brilla a través de la tinta negra. Igual a Sarduy, quien usa la metáfora del Big Bang para describir al lenguaje como una aglomeración de signos que dispersan de un centro vacío hacia afuera, de Campos sugiere que la palabra es una manifestación o un índice de la página vacía. El significado no es ni inherente ni permanente. Nos llaman la atención los puntos de luz que brillan en la página, y que no cesan de ganar y perder el significado mientras forman parte de nuevas constelaciones y contextos.

En Big bang o Xadrez de estrelas, la analogía central se establece entre las palabras y las estrellas, pero el elemento fundamental de su poética constelacional es el expansor que las separa: el espacio blanco de la página detrás de las palabras, igual como el espacio sideral que separa los astros. Las constelaciones poéticas de estos poemas se forman conectando palabras a través del espacio de la página, pero estas conexiones no son permanentes. Hay innumerables maneras de leer estos textos, y después de cada lectura vuelven a ser colecciones de palabras sueltas contra un fondo sordo sin significado. Estos poemas-constelaciones ponen énfasis no sólo en la creación del sentido sino también en su disolución.

Rolando Pérez nota que, en la obra de Sarduy, encontramos en el debate entre los dos modelos distintos del universo — Big Bang y Steady State - un reflejo del debate barroco entre las órbitas circulares y elípticas (Neobaroque Image of Thought 111). Sarduy usaría la idea de la órbita elíptica (del científico barroco Johannes Kepler) como modelo para su propia teoría neobarroca de que el mundo - igual que el lenguaje que lo representa- es imperfecto, desequilibrado, y descentrado. La teoría del Big Bang permite a Sarduy complicar y extender este concepto. Para él, este modelo nuevo describía un universo vasto y desconocido y así parecido al universo misterioso e incompresible del periodo barroco. Sarduy usa esta nueva teoría científica del Big Bang como concepto para entender la lingüística posmoderna - no porque permite articular una relación más concreta entre las palabras y las cosas, sino porque representa una forma más precisa de dramatizar la manera en que el lenguaje, igual como el universo que describe, se define por la incertidumbre, la falta, y hasta el misterio. A Sarduy le interesa la teoría del Big Bang porque nos llama la atención sobre las lagunas en el conocimiento científico. Igual a de Campos, Sarduy busca el punto en que nuestra capacidad de entender cualquier poema se frustra. A este fracaso del sentido los dos poetas dan varios nombres: el vacío, el silencio, la nada, el blanco, la blancura.

Pérez dice que, para Sarduy, la idea de Kepler del órbito elíptico no cuaja con la idea de Galileo del órbito circular, el círculo perfecto en que supuestamente se refleja la mente perfecta de Dios («Severo Sarduy on Galileo» 228). Sarduy convierte a la ciencia barroca en poesía neobarroca, e igual a estos científicos barrocos Sarduy no hace ningún esfuerzo para separar el lenguaje de la ciencia del lenguaje de la espiritualidad. Como de Campos, Sarduy yuxtapone su asombro ante la astronomía con el misterio del misticismo orientalista. Varios conceptos taoistas y budistas 
como maya y sûnyatâ son de suma importancia para Sarduy —especialmente, como nos señala Gustavo Guerrero, en su uso de la idea del vacío5. Mientras Sarduy claramente recicla el misticismo del Catolicismo barroco, su tratamiento del silencio, la ausencia, y el vacío debe mucho al Budismo y el Zen. De forma parecida, durante su periodo neobarroco, de Campos frecuentemente combina el cientifismo y positivismo de su obra concretista con un interés en la capacidad del lenguaje para desafiar a la razón. En Xadrez de estrelas, aparecen varios poemas cortos como «bis in ídem» (1971):

garças no papel

contra um branco
mais seda
o branco
esgarça

Como Blanco de Octavio Paz, este poema identifica y nombra el espacio blanco en que se encuentra. Al mismo tiempo que de Campos nos llama la atención a la materialidad de las palabras, también juega con la posibilidad de que el lenguaje puede volverse transparente. Mientras las palabras, como garzas, flotan por la página, se convierten en una vacuidad que rasga (esgarça) otra vacuidad. Así, «Bis in ídem» imita al koan budista, formando una imagen imposible de comprender.

Galáxias, un poema en prosa épico y el magnum opus del periodo Neobarroco de Haroldo de Campos, representa una partida del uso minimalista de la página que caracterizaba su periodo concretista, pero igual mantiene su énfasis en la presencia visual del espacio blanco. Cada página del texto se enfrenta a una página blanca. Mientras en Galáxias de Campos ya no usa el espacio blanco para crear constelaciones de palabras y fonemas, su uso de la página vacía enfatiza la distancia que separa los fragmentos separados del texto. Marjorie Perloff dice que, a diferencia de la obra concretista de de Campos, Galáxias ya no trata al espacio gráfico de la página como elemento estructural (Perloff «Refiguring» 51). Sin embargo, el título del libro sugiere que la página blanca todavía representa el espacio interestelar. Con cada lectura navegamos por este espacio de forma distinta y así producimos una obra única.

Mientras el término "constelación» sugiere una relación visual entre las palabras de un poema, el término "galáxias» sugiere una relación similar pero en una escala más grande. Para de Campos, la imagen de la constelación encarna su estética concretista temprana, pero el poeta adopta la imagen de la galáxia para describir la poética excesiva, expansiva, y rizomática de su obra neobarroca. Como carece de toda puntuación, numeración de páginas, y uso de mayúsculas, el efecto visual de Galáxias es de la repetición y la desorientación. De Campos incluye una introducción y una conclusión, pero dentro de este marco los textos coexisten sin ningún orden fijo ni prescrito.

El lenguaje de Galáxias, lleno con neologismos y juegos de palabra, siempre parece estar en proceso de metamorfosearse. Así, la mutación y la dispersión de las palabras son a la vez una deriva semántica y una deriva galáctica. Igual a Big bang de Sarduy, el tropo central de Galáxias es el libro-como-viaje, y la experiencia de navegarlo se caracteriza por la desorientación y navegación al azar. Los textos mismos, como los idiomas en que se escriben, siempre están a la deriva. Mientras los leemos, nos perdimos en el espacio ${ }^{6}$. 


\section{Notas}

${ }^{1}$ Les "blancs» en effet assument l'importance, frappent d'abord; la versification en exige, comme silence alentour, ordinairement, au point qu'un morceau, lyrique ou de peu de pieds, occupe au milieu, le tiers environ $d u$ feuillet; je ne transgresse cette mesure, seulement la disperse.

${ }^{2}$ Para de Campos las palabras dentro del poema concreto funcionan de acuerdo con lo que Ernest Fenollosa afirma sobre el ideograma (¿qué dice Fenollosa sobre los ideogramas? Valdría la pena aclarar esto un poco más). Esto no siempre coincide con la realidad de los idiomas a los cuales hacen referencia estos pensadores.

${ }^{3}$ When concretists represent what might be taken as a Mallarméan silence, (...) what they in fact achieve is a reification of silence itself, an inversion of the very absence marking the conventional attempt to make a poetry of presence. ${ }^{4}$ Como Sarduy sostiene en una entrevista con Danubio Torres Fierro en 1978, escribir, en sí mismo, es «en tanto que reflejo de la ilusión, en tanto que armadura que reproduce y da a ver la vacuidad de lo real, la vacuidad fundamental de lo más presente y palpable, que es importante» (176). 5 En "La religión del vacío», Gustavo Guerrero dice que el vacío es un concepto central, generativo dentro de la obra de Sarduy. Guerrero señala que aquí vemos la influencia de Octavio Paz. Hablando de «El estampido de la vacuidad», fragmentos textuales de Sarduy que se publicaron despues de muerte, Guerrero dice que «en ellos, la noche del místico español convive con la revelación de la irrealidad del atman o del brahmin, alma universal o conciencia cósmica; en ellos se evoca la muda palabra del carmelita junto al silencio final del Buda, como dos caras de un solo misterio o dos misterios de un solo rostro" (Guerrero 1702). ${ }^{6} \mathrm{~K}$. David Jackson, en su ensayo, Traveling in Haroldo de Campos's Galáxias: A Guide and Notes for the Reader, cita a Ulysses de James Joyce como el modelo más importante para Galáxias, y nos da una guía al texto neobarroco que imita el que creó Stuart Gilbert para el texto de Joyce. Aprovechándose de las categorías de Gilbert, Jackson divide a su tabla en cuatro columnas: el ritmo, la técnica, la escena, y el símbolo. Esta estrategia trata a cada pasaje del texto como una unidad separada. Como nos explica Jackson, cada fragmento así presenta otra voz narrativa, dentro de un momento histórico definido, y en un escenario distinto. Sin embargo, como nos señala Marjorie Perloff, el lenguaje de Galáxias muchas veces deja que la «materia narrada» no se resuelve («Refiguring» 51 ). 


\section{Referencias bibliográficas}

De Campos, A. et al. (2006). Plano piloto para poesía concreta. En Teoría da poesía concreta: textos criticos e manifestos 1950-1960. Sáo Paulo: Atelié.

De Campos, H. (2006). Galáxias. São Paulo: Editora 34. (1976). Xadrez de estrelas: Percurso Textual 1949-1974. São Paulo: Editora Perspectiva.

Guerrero, G. (1999). La religión del vacío. Severo Sarduy obras completas: tomo II. México City: Fondo de Cultura Económica.

Jackson, D. (2007). Traveling in Haroldo de Campos's Galáxias: A Guide and Notes for the Reader. Ciberletras 17, n.p. http://www.lehman. cuny.edu/ciberletras/v17/jackson.htm.

Mallarmé, S. (1994). Collected Poems. Henry Weinfeld (Trans). Berkeley: University of California.

Paz, O. (1974). Los hijos del limo: del romanticismo a la vanguardia. Barcelona: Seix Barral.

PÉREZ, R. (2012). Severo Sarduy and the Neo-Baroque Image of Thought in the Visual Arts. West Lafayette: Purdue University.

Severo Sarduy on Galileo, Kepler, Borromini, and the Coded Language of the Anamorphic Image. Romance Notes 56 ( $\mathrm{n}^{\circ}$ 2), 225-233. Perloff, M. (2012). Refiguring the Poundian Ideogram. Modernist Cultures (no 7.1), 40-55.

SARduY, S. (1974). Big Bang. Barcelona: Tusquets.

Torres Fierro D. (1978). Severo Sarduy: Lluvia fresca bajo el flamboyant. Escandalar 3, 70.

Steiner, W. (1981). Res Poetica: The Problematics of the Concrete Program. New Literary History 12(3), 529-545.

\section{Anderson, Vaughn}

«La cosmología de lo neobarroco: la función de la astronomía dentro de la poesía de Severo Sarduy y 